\title{
0893. High respiratory rate favors pulmonary edema in an experimental model of acute lung injury
}

\author{
J Retamal ${ }^{1,2^{*}}$, JB Borges ${ }^{1}$, F Suarez-Sipmann ${ }^{1}$, A Bruhn², G Hedenstierna ${ }^{3}$, A Larsson ${ }^{1}$ \\ From ESICM LIVES 2014 \\ Barcelona, Spain. 27 September - 1 October 2014
}

\section{Introduction}

The ARDS-net protocol [1], recommends that respiratory rate (RR) could be increased at hypercapnia in order to normalize PaCO2. However, in heterogeneously inflated lungs, e.g., ARDS, at every breath the local alveolar distending forces will be amplified up to 4.5 times in the interphase between collapsed and aerated areas [2]. Thus, a higher RR could exaggerate the cyclic deformations of lung parenchyma and might therefore induce further lung injury. Indeed, animal studies using simultaneous modifications of flow and tidal volume have indicated that low respiratory rates are lung protective [3]. We therefore hypothesized that an isolated increase of RR would augment the development of ventilator induced lung injury (VILI).

\section{Objectives}

To compare VILI development at two clinically relevant RR during protective mechanical ventilation setting, keeping constant flow, tidal volume (VT) and pCO2 levels.

\section{Methods}

Healthy piglets were subjected to a two-hit lung injury model (saline lavages followed by 2 hours of injurious ventilation), and then randomized into two groups: LRR 20 breaths/min $(\mathrm{n}=6)$, and HRR 40 breaths/min $(\mathrm{n}=6)$, and were mechanically ventilated during six hours according to ARDSnet protocol (VT $6 \mathrm{ml} / \mathrm{kg}$, $\mathrm{PEEP} 10 \mathrm{cmH} 2 \mathrm{O}, \mathrm{FiO} 2 \mathrm{0.5}$ ), keeping an inspiratory time of $0.5 \mathrm{sec}$. We used instrumental dead space to keep similar values of $\mathrm{pCO} 2$ in both groups. We assessed

${ }^{1}$ Hedenstierna Laboratory, Uppsala University, Department of Surgical

Sciences, Uppsala, Sweden

Full list of author information is available at the end of the article respiratory mechanics, invasive systemic and pulmonary arterial pressures, volumetric capnography and extravascular lung water (EVLW). At the end of the experiments lungs were excised and wet/dry (W/D) ratio was evaluated.

\section{Results}

Baseline data were similar between groups. No differences in oxygenation, pCO2 levels, or in systemic and pulmonary arterial pressures were observed during the protocol. We observed an increase in dynamic compliance (Fig. 1) and a decrease in EVLW (Fig. 2) over time in the LRR group $(\mathrm{p}<0.05)$, but not in the HRR group. In addition, W/D ratio (Fig. 3) was higher in the HRR group $(\mathrm{p}<0.05)$. Data are expressed as median and ranges.

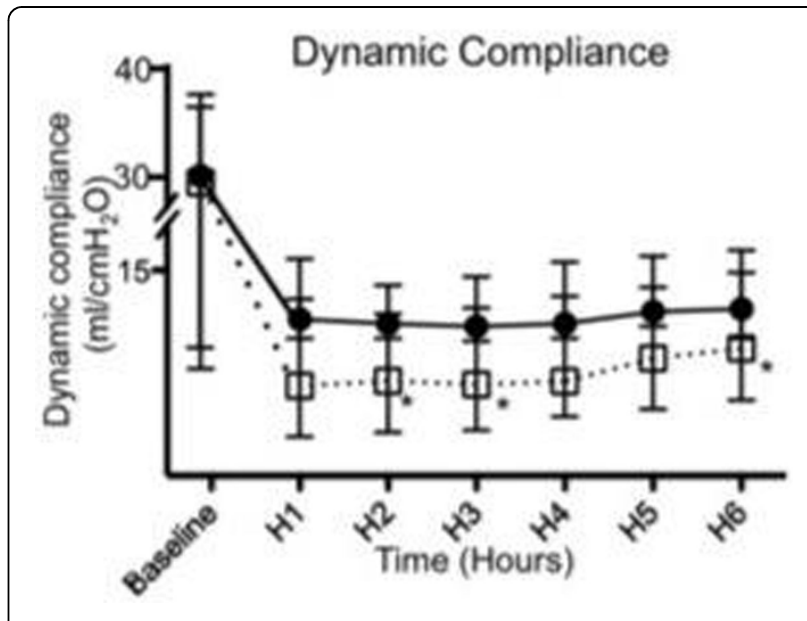

Figure 1 Dynamic compliance 


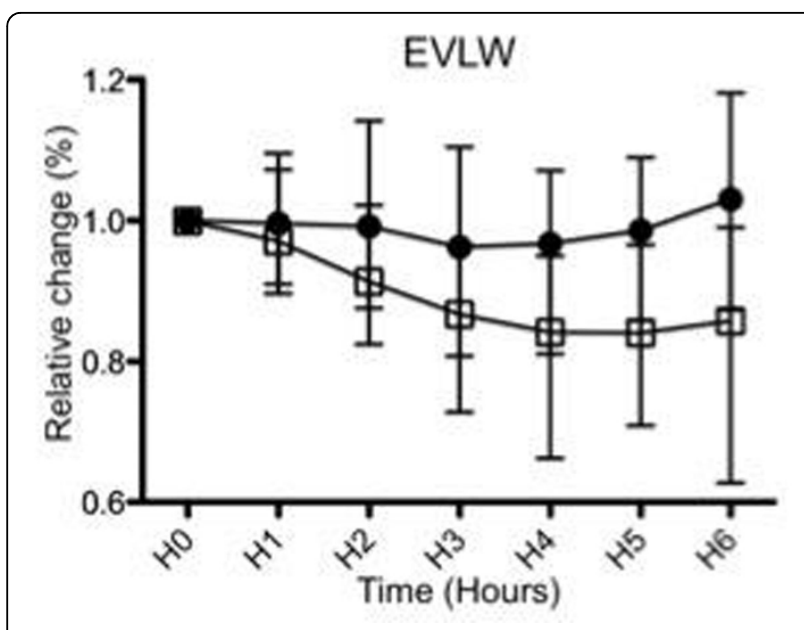

Figure 2 Extravascular lung water (EVLW)

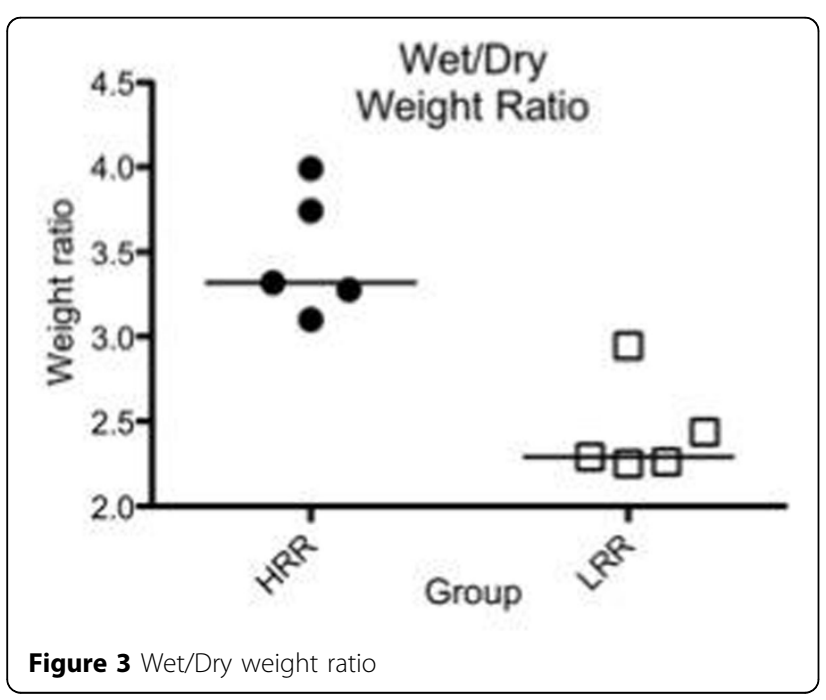

\section{Conclusions}

In our study high respiratory rate reduced lung water clearance, which resulted in an increase of lung water content, indicating that increasing respiratory rate could augment VILI.

\section{Grant acknowledgment}

Beca Cotutela Doctoral CONICYT.

\section{Authors' details}

${ }^{1}$ Hedenstierna Laboratory, Uppsala University, Department of Surgical Sciences, Uppsala, Sweden. ${ }^{2}$ Pontificia Universidad Católica de Chile, Facultad de Medicina, Departamento de Medicina Intensiva, Santiago, Chile. ${ }^{3}$ Hedenstierna Laboratory, Uppsala University, Department of Medical Sciences, Clinical Physiology, Uppsala, Sweden.

Published: 26 September 2014

\section{References}

1. ARDSNet: Ventilation with lower tidal volumes as compared with traditional tidal volumes for acute lung injury and the acute respiratory distress syndrome. N Engl J Med 2000, 342:1301-1308.

2. Mead J: Stress distribution in lungs: a model of pulmonary elasticity. $J$ Appl Physiol 1979, 28:596-608.

3. Vaporidi $\mathrm{K}$ : Effects of respiratory rate on ventilator-induced lung injury at a constant $\mathrm{PaCO} 2$ in a mouse model of normal lung. Crit Care Med 2008, 36(4):1277-1283.

doi:10.1186/2197-425X-2-S1-019

Cite this article as: Retamal et al:: 0893. High respiratory rate favors pulmonary edema in an experimental model of acute lung injury. Intensive Care Medicine Experimental 2014 2(Suppl 1):019.

\section{Submit your manuscript to a SpringerOpen ${ }^{\circ}$ journal and benefit from:}

- Convenient online submission

- Rigorous peer review

- Immediate publication on acceptance

- Open access: articles freely available online

- High visibility within the field

- Retaining the copyright to your article

Submit your next manuscript at $\boldsymbol{s p r i n g e r o p e n . c o m ~}$ 